\title{
Impacts of Protease Treatment on the Contents of Tocopherols and B Vitamins in Peanuts
}

\author{
Rabiatu Bonku ${ }^{1}$, Nona Mikiashvilii ${ }^{1} \&$ Jianmei $\mathrm{u}^{1}$ \\ ${ }^{1}$ Department of family and Consumer Sciences, North Carolina Agricultural and Technical State University, \\ Greensboro, USA \\ Correspondence: Jianmei Yu, Department of Family and Consumer Sciences, North Carolina Agricultural and \\ Technical State University, Greensboro, NC 27411, USA. Tel: 1-336-285-4861. E-mail: jyu@ ncat.edu
}

Received: August 12, 2020

Accepted: September 15, $2020 \quad$ Online Published: September 27, 2020

doi:10.5539/jfr.v9n6p1

URL: https://doi.org/10.5539/jfr.v9n6p1

\begin{abstract}
This study investigated the changes of tocopherols and B vitamins in raw peanuts as a result of protease treatment which was used to reduce peanut allergens. Raw peanut kernels were treated with Alcalase, bromelain, Neutrase and papain separately at different concentrations, vacuum dried, and then ground into paste. The paste was defatted using hexane containing $0.02 \%$ BHT to obtained crude oil and defatted peanut flour which were used for tocopherol and B-vitamin analysis, respectively. The protease treatment significantly reduced the contents of all tocopherols and B-vitamins in the peanuts in enzyme concentration-dependent manner $(\mathrm{P}<0.0001)$. The highest losses of $\alpha-, \gamma$-, and $\delta$-tocopherols were $60.87 \%, 40.60 \%$ and $36.89 \%$, respectively, while the maximum losses of vitamins B1, B2, B3 and B6 were $63.29 \%, 44.83 \%, 40.56 \%$ and $49.59 \%$, respectively. Among tocopherols, $\alpha$-tocopherol was the most affected while $\delta$-tocopherol was the least affected. Among B-vitamins, B1 was the most affected and B3 the least affected. This study demonstrated that although the protease treatment approach (including enzyme treatment and drying) for peanut allergen reduction resulted in different degrees of losses in tocopherols and B vitamins in raw peanuts, the enzyme treated peanuts is still a good source of tocopherols and vitamin B3 comparing to most cooked legumes and vegetable.
\end{abstract}

Keywords: peanuts, protease treatment, tocopherols, B vitamins, vitamin loss, HPLC analysis

\section{Introduction}

Peanuts are excellent source of fat, proteins, vitamins and minerals. The proximate composition of raw peanut kernels includes $47 \%$ fat, $25 \%$ protein, $5 \%$ moisture, $17 \%$ carbohydrate, and $2 \%$ ash (Yadav, Edukondalu, Patel, \& Rao, 2018). Peanuts are rich in vitamin E and some B vitamins. The vitamin E is fat-soluble and the most abundant in peanuts. It functions as an antioxidant for cell membrane protection (Chen et al., 2011; Settaluril et al., 2012) and can be stored in the liver and fatty tissues (Whitney \& Rolfes, 2010). Vitamin E is not a single compound but a group of eight compounds which act as antioxidants maintaining the stability of cell membranes against oxidative stress. These compounds are $\alpha-, \beta-, \gamma-$, and $\delta$-tocopherols and $\alpha-, \beta-, \gamma-$, and $\delta$-tocotrienols, collectively known as tocochromanols (Ahsan et al., 2015). The main tocopherols in peanuts were reported to be $\alpha$-, $\gamma$ - and $\delta$ - tocopherol with $\delta$ - tocopherol having the least concentration (Medina-Juárez et al., 2009). The concentrations of $\alpha-, \gamma$-, and $\delta$-tocopherol in peanut oil are 8.86-30.4, $0-0.38,3.50-19.2,0.85-3.10$ $\mathrm{mg} / 100 \mathrm{~g}$ oil, respectively (Shahidi \& Costa De Camargo, 2016). The concentration ranges of these tocopherols in peanuts are 11.9-25.3, 10.4-34.2 and 0.58-2.5 mg/100g (Ahmed \& Young, 1982). The B vitamins include B1 (thiamine), B2 (riboflavin), B3 (niacin), B5 (pantothenic acid), B6 (pyridoxine), B8 (biotin), B9 (folic acid), and B12 (cyanocobalamine) are water soluble. They function as coenzymes during biochemical processes in the body. Peanut is a rich source of thiamine (B1), niacin (B3) and choline (B4). Vitamin B4 (choline) is a vitamin-like nutrient which can be synthesized by the body provided the precursors folic acid and vitamin B12 are sufficient (Cai et al., 2019). However, there is limited information on the determination of B vitamins in peanut because the analysis of B vitamins (extraction and purification methods) in oilseed is very tedious. Another major challenge is the tendency of the vitamin degradation due to exposure to air and light (Trang, 2013). The contents of vitamin B1, B2, B3 and B6 in Virginia peanuts were reported by the United States Department of Agriculture (USDA) database as $0.653,0.131,12.375$, and $0.346 \mathrm{mg} / 100 \mathrm{~g}$ (USDA, 2018). Peanut oil also contains a substantial amount of phytosterols which have anticancer properties and impair the absorption of cholesterol 
from the digestive tract (Awad et al., 2000; Abumweis et al., 2008; Hashemian et al., 2017). According to the USDA nutrient composition database, $100 \mathrm{~g}$ peanuts consumed may provide up to $75 \%$ RDA of niacin, $60 \%$ RDA of folate, $53 \%$ RDA of thiamine, $10 \%$ RDA of riboflavin, $35 \%$ RDA of pantothenic acid, $27 \%$ RDA of pyridoxine, $55.5 \%$ RDA of vitamin E (USDA, 2018).

Although peanut contains about $25 \%$ protein, the majority of the protein is allergenic which affect $2-2.5 \%$ of populations in the developed countries. In the United States $2.5 \%$ children and $1.8 \%$ of adults are allergic to peanut (Jiang et al., 2018; Gupta et al., 2019). Peanut allergy prevalence in Europe is about $2.2 \%$ (Nwaru et al., 2014). Peanut allergy is one of the most fatal food allergies, which accounts for about $59 \%$ death caused by food allergy (Bock et al., 2007). Scientists have proposed different approaches to mitigate peanut allergy. Proteolytic hydrolysis using non-specific proteases such as Alcalase, bromelain, Neutrase and papain has been reported to tremendously reduce the contents of major allergenic proteins such as Ara h 1, Ara h 2 and Ara h 6 in the peanuts (Yu et al., 2015; Yu \& Mikiashvili, 2020). However, the effect of the proteolytic hydrolysis on the nutrient composition is unknown. The purpose of this study was to evaluate the influence of protease treatment on the tocopherol contents in peanut kernels.

\section{Materials and Methods}

\subsection{Materials}

Raw Virginia peanuts were purchased from Good Earth Peanut Company (Skippers, VA, USA). The enzymes used in the study, including Alcalase, bromelain, Neutrase, and papain were purchased from Fisher Scientific (Suwanee, GA, USA). These are non-selective proteases. The standards of B Vitamins (including B1, B2, B3, B6) and tocopherols (including the $\alpha-, \gamma-$, and $\delta$-tocopherols) were all purchased from Sigma-Aldrich (St. Louis, MO, USA). The chemical reagents and solvents including hexane, methanol, butylated hydroxyanisole (BHA), butylated hydroxytoluene (BHT), trichloroacetic acid (TCA), hydrochloric acid ( $\mathrm{HCl}$ ), sodium dioctylsulfosuccinate, formic acid, potassium hydroxide $(\mathrm{KOH})$ were all purchased from the Fisher Scientific (Hampton, NH, USA).

\subsection{Enzymatic Treatment}

Raw peanuts (50 g each) were treated with individual proteases (Alcalase, bromelain, Neutrase, and papain) separately in phosphate buffer $(20 \mathrm{mM})$ at different concentrations and incubated at the optimal temperature and $\mathrm{pH}$ of each enzyme for 3 hours as described previously (Yu \& Mikiashvili, 2020). The concentrations of Alcalase, bromelain, Neutrase and papain used in different treatments were shown in Table 1. The optimal pHs and temperatures of Alcalase, papain, Neutrase, and bromelain are 7.5, 6.0, 7.0, and 7.0 and 50, 48, 50, and $45{ }^{\circ} \mathrm{C}$, respectively. Due to the solubility limitation, the maximum concentrations of bromelain and papain could be used in the treatment were $0.2 \%$ and $0.5 \%(\mathrm{w} / \mathrm{w})$, respectively. The treated peanut kernels were dried in a vacuum oven at $75{ }^{\circ} \mathrm{C}$ for $16-18$ hours to remove the moisture, ground into paste and stored at $4{ }^{\circ} \mathrm{C}$. The untreated raw peanut sample was used as control, and untreated vacuum dried peanut sample was used to examine the influence of vacuum drying on the contents of tocopherols and B vitamins in the peanuts.

Table 1. Concentrations of proteases used in the study

\begin{tabular}{lcccc}
\hline & \multicolumn{4}{c}{ Enzyme Concentration (\%) } \\
\cline { 2 - 5 } Treatment & Alcalase* & Bromelain $\dagger$ & Neutrase* & Papain $\dagger$ \\
\hline T1 & 1.0 & 0.02 & 0.2 & 0.1 \\
T2 & 2.0 & 0.04 & 0.4 & 0.2 \\
T3 & 3.0 & 0.08 & 0.8 & 0.3 \\
T4 & 3.5 & 0.16 & 1.2 & 0.4 \\
T5 & 4.0 & 0.20 & 1.6 & 0.5 \\
\hline
\end{tabular}

*Alcalase and Neutrase were liquid forms and their concentrations (enzyme to peanut ratios) were volume to weight (v/w).

$\dagger$ Bromelain and papain were solid forms and their concentrations (enzyme to peanut ratios) were weight to weight $(w / w)$.

\subsection{Extraction of Peanut Oil}

Tocopherols are fat-soluble and they concentrate in the oil. Therefore, peanut oil was extracted using hexane containing $0.02 \%$ butylated hydroxytoluene (BHT) for tocopherol quantification. The peanut paste $(20.00 \mathrm{~g})$ was weighed into a glass flask and then $30 \mathrm{ml}$ of the extraction solvent was added and magnetic stirred for 1 hour. 
The sample was centrifuged at $3000 \mathrm{~g}$ for 15 minutes using a $5810 \mathrm{R}$ centrifuge (Eppendorf Corporation, Hamburg, Germany) and the supernatant was poured into a pre-weighed evaporating flasks. The precipitate was re-extracted by another $30 \mathrm{ml}$ of solvent. The combined supernatant was concentrated at $40{ }^{\circ} \mathrm{C}$ under reduced pressure using a R-300 Rotavapor (Büchi, Flawil, Switzerland) to remove the hexane. The resulted oil was quantified, collected into an amber glass vial and stored at $4{ }^{\circ} \mathrm{C}$ for tocopherol analysis. The oil yield was calculated based on the amount of oil extracted and the weight of peanut paste for oil extraction. Both oil extraction and concentration were conducted under dim light.

\subsection{Extraction and Purification of B Vitamins}

The precipitates from oil extraction were dried in a 285A Isotemp vacuum oven (Fisher Scientific (Suwanee, GA, USA) at $40{ }^{\circ} \mathrm{C}$ for 3 hours to obtain the defatted peanut flour, which were stored at $4{ }^{\circ} \mathrm{C}$ for the $\mathrm{B}$ vitamins extraction. The method described by Woollard \& Indyk (2002) was used to extract B vitamins from peanut flour. The defatted peanut flour $(1.00 \mathrm{~g})$ was suspended in $5 \mathrm{ml}$ warm deionized water $\left(37^{\circ} \mathrm{C}\right)$, and then $10 \mathrm{ml}$ of 0.3 M TCA was added. The sample was shaken in a GmbH SW22 water bath (Julabo, Seelbach, Germany) for 15 minutes at $37^{\circ} \mathrm{C}$, and then centrifuged at $3000 \mathrm{~g}$ for 10 minutes. The supernatant was purified using Sep-Pak Vac solid-phase extraction (SPE) columns $\left(3 \mathrm{cc}, \mathrm{C}_{18}\right)$ where acidified water $(\mathrm{pH} 4.2)$ and methanol were used as mobile phases for elution. The elute (purified sample) was concentrated using a rotary evaporator at $40{ }^{\circ} \mathrm{C}$ to remove the methanol. The concentrated sample was transferred into an amber glass vial and stored at $4{ }^{\circ} \mathrm{C}$ for analysis within one week. For each peanut flour sample, the extraction was conducted in triplicate. The extraction, purification and concentration were conducted under dim light.

\subsection{Determination of Tocopherols in Peanut Oils}

For each peanut oil extract, 100mg sample was diluted with a mixture of hexane: methanol (20:80, v/v) to $1 \mathrm{ml}$. The sample was vortex mixed and filtered through a $0.22 \mu \mathrm{m}$ glass fiber syringe filter into an amber HPLC vial and then directly injected into an HPLC system (Waters Corporation., Milford, MA) equipped with a UV-Vis Dual Wavelength Detector and a Florescence Detector. The tocopherols in the sample were separated on an Accucore XL C18 column ( $3 \mathrm{~mm} \times 150 \mathrm{~mm}, 4 \mu \mathrm{m})$, eluted with $96 \%$ methanol in water $(\mathrm{v} / \mathrm{v})$ at $0.8 \mathrm{ml} / \mathrm{min}$ and the peak areas were detected by the UV-Vis detector at $230 \mathrm{~nm}$. The tocopherols were identified by comparing the retention times of samples with the corresponding standards. The concentrations of tocopherols in the diluted oil samples were calculated using their calibration curves, and then converted to mg per $100 \mathrm{~g}$ peanuts according to dilution factor and oil yield. The standard curve of each tocopherol was obtained using a set of properly diluted standard solutions with concentrations of $1,5,10,15$, and $20 \mu \mathrm{g} / \mathrm{ml}$ under the same chromatography condition for the peanut oil samples. The total $\alpha$-tocopherol in oil sample was the sum of $\alpha$-tocopherol and $\alpha$-tocopherol acetate. For each peanut oil extract, the analysis was conducted in triplicate.

\subsection{Determination of B Vitamins}

The purified B vitamin extracts were quantitatively diluted using 0.3 M TCA solution. An aliquot of the sample was filtered through a $0.22 \mu \mathrm{m}$ syringe filter and analyzed by a Waters HPLC system. The B vitamins were separated by a Kinetex $\mathrm{C}_{18}$ column $(150 \times 4.6 \mathrm{~mm}, 5 \mu \mathrm{m})$ and eluted with mobile phase isocratically at $1 \mathrm{ml} / \mathrm{min}$. The mobile phase for thiamine (B1) elution was prepared by dissolving $1.00 \mathrm{~g}$ of sodium dioctylsulfosuccinate in $550 \mathrm{ml}$ methanol containing $10 \mathrm{ml}$ of concentrated formic acid. The solution was adjusted $\mathrm{pH}$ to 4.4 with $50 \%$ $\mathrm{KOH}$ solution, and then diluted to $1 \mathrm{~L}$ using DI water. The mobile phase for riboflavin (B2), nicotinic acid, nicotinamide, and pyridoxine (B6) elution was prepared by dissolving $1.00 \mathrm{~g}$ of sodium dioctylsulfosuccinate in $250 \mathrm{ml}$ methanol containing $10 \mathrm{ml}$ of concentrated formic acid, the solution was adjusted $\mathrm{pH}$ to 2.8 , and then diluted to $1 \mathrm{~L}$ with DI water. The B1 was detected by the UV-Vis detector at $254 \mathrm{~nm}$, while the B2, nicotinic acid, nicotinamide, and B6 were detected by the Fluorescence detector at the excitation wavelength of $290 \mathrm{~nm}$ and the emission wavelength of $390 \mathrm{~nm}$. The standard curve of each B vitamin was obtained using a set of properly diluted standard solutions of the B vitamin. The concentration ranges of B1, B2 and B6 were 1-25 $\mu \mathrm{g} / \mathrm{ml}$, $0.025-0.025 \mu \mathrm{g} / \mathrm{ml}$, and $1-100 \mu \mathrm{g} / \mathrm{ml}$, respectively. Vitamin B3 includes nicotinic acid and nicotinamide, and their concentrations for standard curve development were $1-12 \mu \mathrm{g} / \mathrm{ml}$ and $1-100 \mu \mathrm{g} / \mathrm{ml}$, respectively. The concentration of each B vitamin in the extract was calculated by using the peak area and the corresponding calibration equation, and then converted to $\mathrm{mg}$ per $100 \mathrm{~g}$ peanuts according to the dilution factor, extract volume and sample weight.

\subsection{Recovery Test}

For the tocopherols, a known amount of a specific tocopherol standard was added to $100 \mathrm{mg}$ of peanut oil with known concentration of the tocopherol. The mixture was then diluted to $1 \mathrm{ml}$ with hexane: methanol $(20: 80, \mathrm{v} / \mathrm{v})$ and the tocopherol concentration was determined as described in subsection 2.5. For the B vitamins, $1.000 \mathrm{~g}$ of 
the defatted peanut flour was suspended in $5 \mathrm{ml}$ warm distilled water at a temperature of $37^{\circ} \mathrm{C}$ in an Elementary flask and a known amount of a specific B vitamin standard was added to the suspension under constant stirring, and then stored at $4{ }^{\circ} \mathrm{C}$ overnight with stopper on. The sample was warmed to $37^{\circ} \mathrm{C}$. The vitamin was extracted and purified as described in subsection 2.4, and then analyzed by HPLC, as described in subsection 2.6. The recovery rate for each vitamin was calculated by the equation below and used to adjust the content the specific vitamin in the peanut oil sample. For each vitamin, the recovery experiment was conducted in triplicate.

$$
\text { Recovery }(\%)=(\mathrm{Ct}-\mathrm{Cp}) * 100 /(\mathrm{Ca}+\mathrm{Cp})
$$

Where $\mathrm{Ct}$ - the total vitamin content determined, $\mathrm{Cp}$ - the vitamin content in peanut oil or flour, $\mathrm{Ca}$ - the amount of vitamin added.

\subsection{Data Analysis}

The results were expressed as mean \pm standard deviation and statistically analyzed using ANOVA using SAS version 9.4 (SAS Institute, Cary, NC, USA). The means were compared using Duncan Multiple Range tests with a significance level of $<0.05$.

\section{Results}

\subsection{Oil Yield of Extraction Method}

The oil yield was used as an indicator to evaluate whether the oil was completely extracted from peanuts because the tocopherol content of peanut was determined using extracted oil. Table 2 shows that oil yields of untreated and treated peanuts were in the range of $48-52 \%$ which indicate that the oil in peanut samples was completely extracted by the method and procedure used in this study because the crude fat content of raw peanuts (all types) is reported to be $49.24 \pm 0.30 \%$ (USDA, 2015).

Table 2. Oil yield of protease treated and untreated peanut samples

\begin{tabular}{|c|c|c|c|c|c|}
\hline \multirow[b]{2}{*}{ Treatment } & \multicolumn{5}{|c|}{ Oil Yield (\%) } \\
\hline & Untreated & Alcalase & Bromelain & Neutrase & Papain \\
\hline UNT & 50.81 & - & - & - & - \\
\hline UNT-VD & 48.00 & - & - & - & - \\
\hline T1 & - & 48.60 & 51.35 & 48.75 & 49.34 \\
\hline $\mathbf{T 2}$ & - & 49.65 & 49.82 & 49.39 & 50.09 \\
\hline T3 & - & 50.01 & 49.35 & 50.47 & 51.46 \\
\hline T4 & - & 51.30 & 51.24 & 48.02 & 52.00 \\
\hline T5 & - & 50.96 & 51.42 & 49.67 & 50.15 \\
\hline
\end{tabular}

Note: UNT: untreated raw peanuts; UNT-VD: untreated vacuum dried raw peanut; T1, T2, T3, T4 and T5-represent 5 different protease concentrations.

\subsection{Recovery of Tocopherols and B Vitamins during Extraction, Purification, and Analysis}

The recovery tests were conducted to validate the vitamin extraction, purification, and HPLC methods used in the study to ensure the accurate quantification. The mean recoveries for $\alpha-, \alpha_{\mathrm{A}^{-}}, \gamma-$, and $\delta$-tocopherols added to the peanut oil sample was $106 \%, 206.61 \%, 111 \%$, and $116 \%$, respectively, while the mean recoveries for thiamine (B1), riboflavin (B2), niacin (B3) and pyridoxine (B6) added to the peanut flour samples were $105 \%$, $108 \%, 105 \%$, and $96 \%$, respectively. This indicates that the contents of vitamins with exception of pyridoxine in the peanuts were overestimated and adjustments were needed. The concentrations of each vitamin in the peanuts reported in this study were adjusted with the recovery rate of the specific vitamin.

\subsection{Effect of Alcalase Treatment on the Contents of Tocopherols and B Vitamins in Raw Peanuts}

Figure 1 shows that $\alpha-\mathrm{T}$ and B3 were the richest tocopherol and B vitamin in peanuts and Alcalase treatment resulted in significant reductions of all tocopherols and $\mathrm{B}$ vitamins in enzyme concentration-dependent manner $(\mathrm{P}<0.0001)$. Figure 1A shows that $\alpha-\mathrm{T}$ and $\mathrm{y}-\mathrm{T}$ were significantly reduced compared to the untreated at lower Alcalase concentrations (T1 - T3); increasing Alcalase concentration from T3 to T5 resulted in further reduction in $\alpha-\mathrm{T}$ and $\delta$ - $\mathrm{T}(\mathrm{P}<0.05)$ but not $\mathrm{\gamma}$-T contents. Figure 1B shows that the contents of all tested $\mathrm{B}$ vitamins in peanuts were significantly reduced at low Alcalase concentration $\mathrm{T} 1(\mathrm{P}<0.0001)$, but the effects of Alcalase concentration on B1, B2, B3 and B6 varied. The B6 content decreased almost linearly with increasing Alcalase concentration $\left(\mathrm{R}^{2}=0.939, \mathrm{P}<0.05\right)$, while the changes of $\mathrm{B} 1, \mathrm{~B} 2$ and $\mathrm{B} 3$ with Alcalase concentration were nonlinear. The B1 contents were not significantly different at enzyme concentrations T1, T2 and T3, but were 
significantly lower at T4 and T5 $(\mathrm{P}<0.05)$. The B2 content was not affected until Alcalase concentration T3 $(\mathrm{P}<0.05)$.
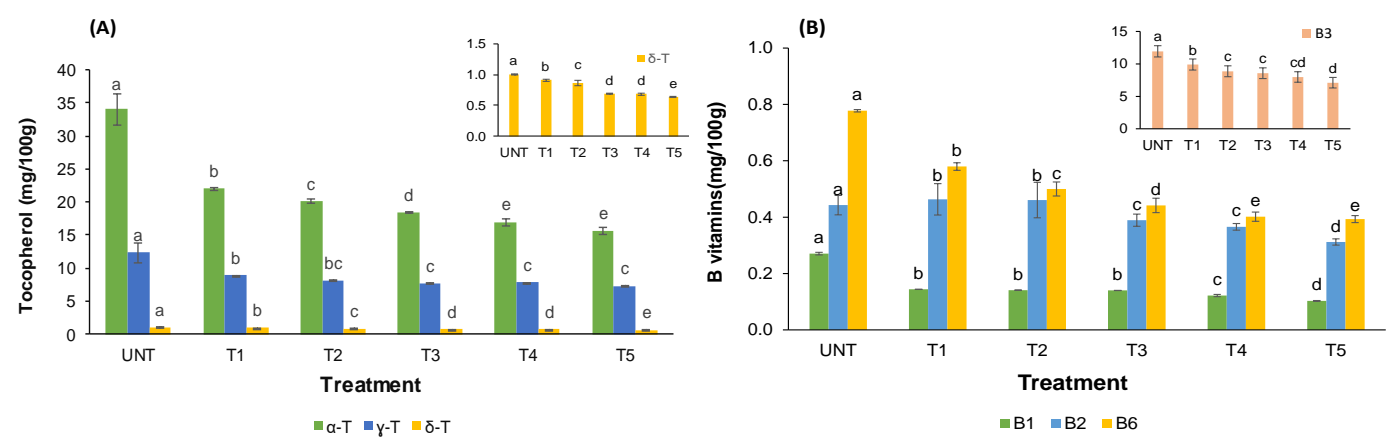

Figure 1. Effects of Alcalase treatment on concentrations of Tocopherols (A) and B-vitamins (B) in raw peanuts. Different letters on the top of data bars for the same vitamin indicate significant differences $(\mathrm{P}<0.05, \mathrm{n}=3)$. UNT: untreated sample, T1-T5: Alcalase concentrations (T1-1\%, T2-2\%, T3-3\%, T4-3.5\% and T5-4\%)

\subsection{Effect of Bromelain Treatment on the Contents of Tocopherols and B Vitamins in Raw Peanuts}

Figure 2A shows that the treatment of raw peanuts with bromelain resulted in a significant decrease in the $\alpha$-T content at all enzyme concentrations, and the reduction of $\alpha$-T increased with increasing bromelain concentration $(\mathrm{P}<0.0001)$. Although bromelain treatment also decreased $\mathrm{\gamma}-\mathrm{T}$ and $\delta$-T contents in the peanuts, particularly at high enzyme concentration (T5) $(\mathrm{P}<0.05)$, the influence was much smaller than that on $\alpha$-tocopherol within the range of bromelain concentration used in this study. Figure 2B shows that the contents of all tested B vitamins were significantly reduced at low bromelain concentration (T1) compared with those in untreated samples (P $<0.0001)$. However, increasing bromelain concentration from T1 to T3 did not significantly increase B vitamin loss with exception of B2. Slight but statistically significant reductions of B1, B2, B6 and B3 contents were observed as enzyme concentration increased to T4 and T5 $(\mathrm{P}<0.05)$. Data in Figure 2 indicate that the effects of bromelain treatment on tocopherol and B vitamins are limited with exceptions of $\alpha$-tocopherol and vitamin B1.
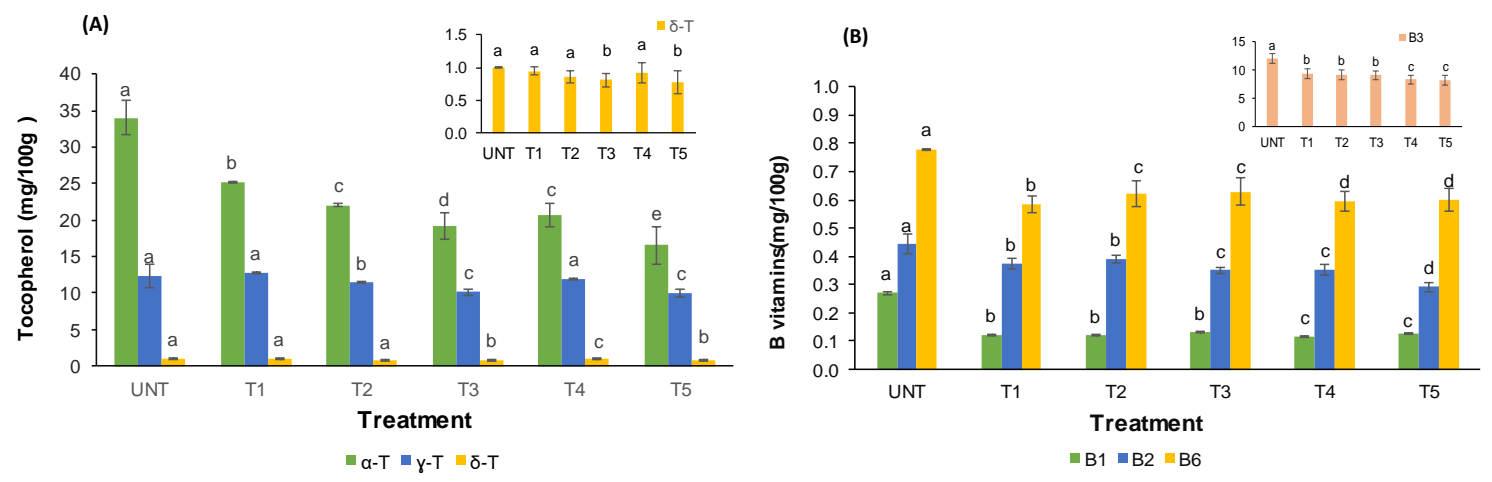

Figure 2. Effects of bromelain treatment on concentrations of Tocopherols (A) and B-vitamins (B) in raw peanuts. Different letters on the top of data bars for the same vitamin indicate significant difference $(\mathrm{P}<0.05$, $\mathrm{n}=3$ ). UNT: untreated sample, T1-T5: bromelain concentrations (T1-0.02\%, T2-0.04\%, T3-0.08\%, T4-0.16\% and $\mathrm{T} 5-0.20 \%)$

\subsection{Effect of Neutrase Treatment on the Contents of Tocopherols and B Vitamins in Raw Peanuts}

Figure 3A shows that at low concentration T1 Neutrase treatment resulted in significant reduction of $\alpha$-T and $\gamma$-T contents in the peanuts $(\mathrm{P}<0.0001)$; there was no significant difference in $\alpha$-T among samples treated at Neutrase concentrations T1, T2, and T3; but further reduction of $\alpha$-T was observed when enzyme concentration increased to T4 and T5 $(\mathrm{P}<0.05)$. Similar changes of $\gamma$-T with Neutrase level were observed. The $\delta$-T contents of the peanuts treated at lower Neutrase concentrations (T1-T3) were significantly higher than that of untreated 
$(\mathrm{P}<0.05)$, but it decreased as Neutrase concentration increasing. The $\delta$-T content at T4 and T5 was slightly but significantly lower than that of untreated $(\mathrm{P}<0.05)$. Figure 3B depicts that Neutrase treatment of peanuts resulted in significant reduction in $\mathrm{B} 1, \mathrm{~B} 2, \mathrm{~B} 3$, and $\mathrm{B} 6$ contents $(\mathrm{P}<0.0001)$. Similar to the bromelain treatment, significant loss of B vitamins with exception of B2 was observed at low Neutrase concentration (T1) $(\mathrm{P}<0.05)$. There was no further reduction in B1 and B3 when the enzyme concentration increased from $\mathrm{T} 1$ to $\mathrm{T} 3$, but further reductions of $\mathrm{B} 1$ and $\mathrm{B} 3$ were observed at $\mathrm{T} 4$ and $\mathrm{T} 5(\mathrm{P}<0.05)$. The significant reduction of $\mathrm{B} 2$ content was observed at T2 and higher Neutrase concentration. B6 content was significantly reduced at $\mathrm{T} 1$ but remained constant until T5.
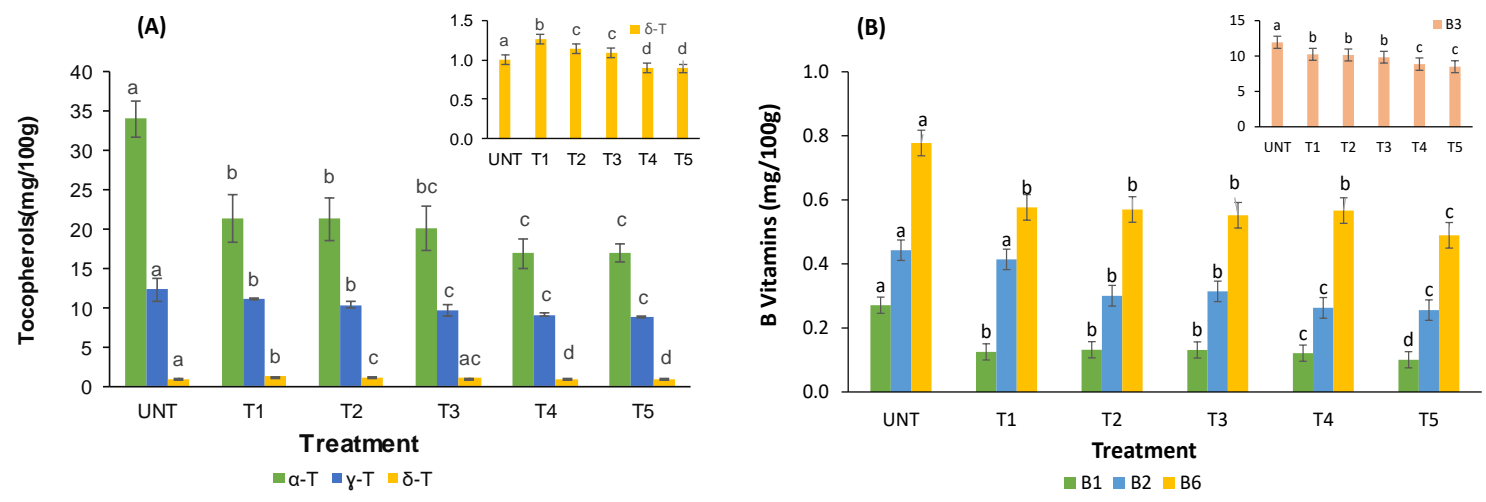

Figure 3. Effects of Neutrase treatment on concentrations of Tocopherols (A) and B-vitamins (B) in raw peanuts. Different letters on the top of data bars for the same vitamin indicate significant differences $(\mathrm{P}<0.05, \mathrm{n}=3)$. UNT: untreated sample, T1-T5: Neutrase concentrations (T1-02\%, T2-0.4\%, T3-0.8\%, T4-1.2\%, T5-1.6\%)

\subsection{Effect of Papain Treatment on the Contents of Tocopherols and B Vitamins in Raw Peanuts}

Figure 4A exhibits that the papain treatment of peanuts had significant impacts on the contents of all tocopherols compared with untreated $(\mathrm{P}<0.0001)$. The $\alpha$-T content decreased with increasing papain concentration but was not significantly different at enzyme concentrations T2 and T3. The content of $\gamma$-T was not reduced until papain concentration T2, and then remained unchanged until T5 $(\mathrm{P}<0.05)$. Similar to Neutrase treated peanuts, the $\delta$ - $\mathrm{T}$ content increased significantly $(\mathrm{P}<0.05)$ at $\mathrm{T} 1$, then gradually decreased with increasing papain concentration, and was lower than that of untreated peanuts at T5 $(\mathrm{P}<0.05)$. Figure 4B shows that papain treatment significantly reduced the contents of all $\mathrm{B}$ vitamins in peanuts at low papain concentration $\mathrm{T} 1(\mathrm{P}<0.0001)$. The $\mathrm{B} 1$ content decreased significantly with increasing papain concentration. However, B2 and B3 were not significantly reduced until papain concentration T4. Although B6 was significantly reduced at T1, its level remained constant until T5. Therefore, the effects of papain concentration on B2, B3, and B6 were not as strong as those on B1.
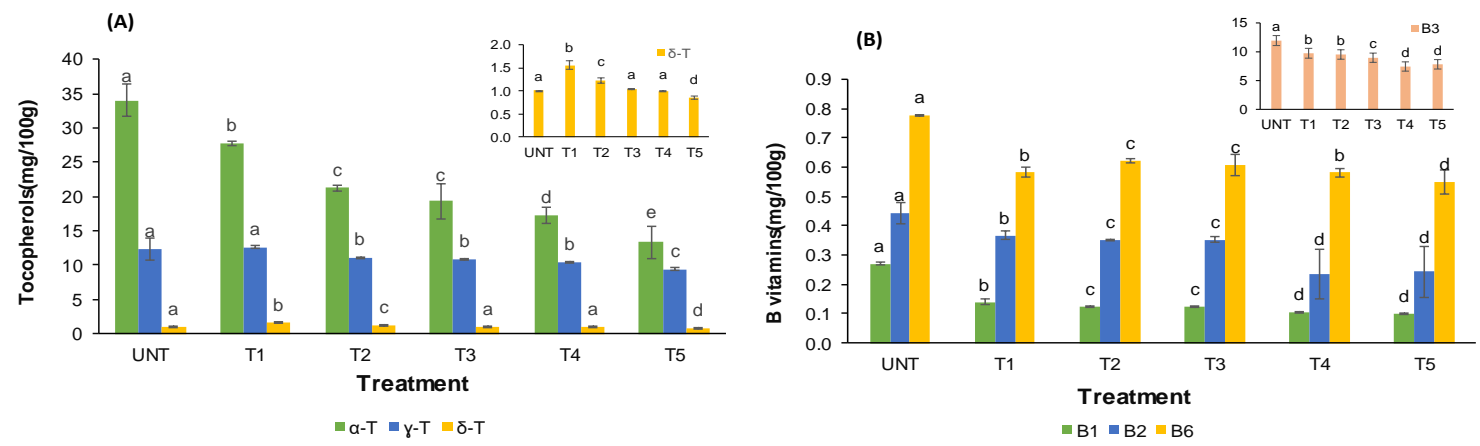

Figure 4. Effects of papain treatment on concentrations of Tocopherols (A) and B-vitamins (B) in raw peanuts. Different letters on the top of data bars for the same vitamin indicate significant differences $(P<0.05, n=3)$. UNT: untreated sample (control), T1-T5: papain concentrations (T1-0.1\%, T2-0.2\%, T3-0.3\%, T4-0.4\% and T5-0.5\%)

\subsection{Vitamin B3 Content of Raw Peanuts Treated with different Proteases}

Vitamin B3 (niacin) consists of nicotinic acid and nicotinamide; therefore, the impacts of different protease 
treatments on nicotinic acid and nicotinamide are given separately from other B vitamins. Table 3 shows that the nicotinamide, nicotinic acid, and total niacin content of untreated peanuts were $1.99,9.94$, and $11.94 \mathrm{mg} / 100 \mathrm{~g}$ of peanuts, respectively. All enzyme treatments resulted in significant reductions of nicotinamide and nicotinic acid, thus the content of vitamin B3 $(\mathrm{P}<0.0001)$. Regardless of the type of protease, the B3 reduction increased with enzyme concentration $(\mathrm{P}<0.05)$. The treatment with Alcalase had the strongest impact on the $\mathrm{B} 3$ level, followed by papain, bromelain, and Neutrase.

Table 3. Nicotinamide, nicotinic acid, and total vitamin B3 contents of raw peanut treated with different proteases

\begin{tabular}{llllll}
\hline Enzyme & Treatment & $\begin{array}{l}\text { Enzyme } \\
\text { conc. }(\%)\end{array}$ & $\begin{array}{l}\text { Nicotinamid } \\
\text { mg/100g Peanuts }\end{array}$ & $\begin{array}{l}\text { Nicotinic acid } \\
\text { mg/100g Peanuts }\end{array}$ & $\begin{array}{l}\text { Total B3 vitamins } \\
\text { mg/100g Peanuts }\end{array}$ \\
\hline Alcalase & UNT & 0 & $1.99 \pm 0.05^{\mathrm{a}}$ & $9.94 \pm 0.79^{\mathrm{a}}$ & $11.94 \pm 0.78^{\mathrm{a}}$ \\
& T1 & 1.0 & $1.66 \pm 0.08^{\mathrm{b}}$ & $8.25 \pm 0.13^{\mathrm{b}}$ & $9.92 \pm 0.13^{\mathrm{b}}$ \\
& T2 & 2.0 & $1.52 \pm 0.02^{\mathrm{c}}$ & $7.34 \pm 0.27^{\mathrm{bc}}$ & $8.87 \pm 0.27^{\mathrm{c}}$ \\
& T3 & 3.0 & $1.52 \pm 0.02^{\mathrm{c}}$ & $7.04 \pm 0.08^{\mathrm{c}}$ & $8.57 \pm 0.09^{\mathrm{c}}$ \\
& T4 & 3.5 & $1.12 \pm 0.01^{\mathrm{d}}$ & $6.86 \pm 0.55^{\mathrm{c}}$ & $7.98 \pm 0.55^{\mathrm{cd}}$ \\
& T5 & 4.0 & $0.94 \pm 0.01^{\mathrm{e}}$ & $6.15 \pm 0.49^{\mathrm{c}}$ & $7.07 \pm 0.48^{\mathrm{d}}$ \\
Bromelain & T1 & 0.02 & $1.43 \pm 0.013^{\mathrm{b}}$ & $7.89 \pm 0.34^{\mathrm{bc}}$ & $9.32 \pm 0.33^{\mathrm{b}}$ \\
& T2 & 0.04 & $1.40 \pm 0.011^{\mathrm{b}}$ & $7.75 \pm 0.46^{\mathrm{c}}$ & $9.16 \pm 0.46^{\mathrm{b}}$ \\
& T3 & 0.08 & $1.48 \pm 0.032^{\mathrm{c}}$ & $7.54 \pm 0.11^{\mathrm{c}}$ & $9.02 \pm 0.13^{\mathrm{b}}$ \\
& T4 & 0.16 & $1.30 \pm 0.008^{\mathrm{d}}$ & $6.95 \pm 0.27^{\mathrm{c}}$ & $8.25 \pm 0.27^{\mathrm{c}}$ \\
& T5 & 0.20 & $1.19 \pm 0.005^{\mathrm{e}}$ & $6.94 \pm 0.26^{\mathrm{c}}$ & $8.13 \pm 0.26^{\mathrm{c}}$ \\
Neutrase & T1 & 0.2 & $1.62 \pm 0.007^{\mathrm{b}}$ & $8.62 \pm 0.47^{\mathrm{b}}$ & $10.24 \pm 0.47^{\mathrm{b}}$ \\
& T2 & 0.4 & $1.62 \pm 0.045^{\mathrm{b}}$ & $8.52 \pm 0.47^{\mathrm{b}}$ & $10.14 \pm 0.46^{\mathrm{b}}$ \\
& T3 & 0.8 & $1.52 \pm 0.023^{\mathrm{c}}$ & $8.30 \pm 0.45^{\mathrm{bc}}$ & $9.83 \pm 0.48^{\mathrm{b}}$ \\
& T4 & 1.2 & $1.15 \pm 0.043^{\mathrm{d}}$ & $7.69 \pm 0.32^{\mathrm{bc}}$ & $8.85 \pm 0.30^{\mathrm{c}}$ \\
& T5 & 1.6 & $1.21 \pm 0.005^{\mathrm{e}}$ & $7.28 \pm 0.33^{\mathrm{c}}$ & $8.49 \pm 0.33^{\mathrm{c}}$ \\
Papain & T1 & 0.1 & $1.53 \pm 0.005^{\mathrm{b}}$ & $8.21 \pm 0.48^{\mathrm{bc}}$ & $9.75 \pm 0.48^{\mathrm{b}}$ \\
& T2 & 0.2 & $1.54 \pm 0.070^{\mathrm{b}}$ & $7.99 \pm 0.47^{\mathrm{bc}}$ & $9.54 \pm 0.43^{\mathrm{b}}$ \\
& T3 & 0.3 & $1.48 \pm 0.045^{\mathrm{b}}$ & $7.47 \pm 0.24^{\mathrm{c}}$ & $8.95 \pm 0.21^{\mathrm{c}}$ \\
& T4 & 0.4 & $1.17 \pm 0.013^{\mathrm{c}}$ & $6.26 \pm 0.33^{\mathrm{d}}$ & $7.44 \pm 0.33^{\mathrm{d}}$ \\
& T5 & 0.5 & $1.26 \pm 0.018^{\mathrm{d}}$ & $6.56 \pm 0.21^{\mathrm{dc}}$ & $7.82 \pm 0.21^{\mathrm{d}}$ \\
\hline
\end{tabular}

UNT*: untreated peanut. For a specific protease, data with different superscripts in the same column are significantly different at $\mathrm{P}<0.05$.

\subsection{Percentage Loss of Vitamins in Raw Peanuts Due to Protease Treatments}

Table 4 shows that the loss of extractable vitamins in peanuts caused by protease treatments varied with the type and concentration of protease, as well as type of vitamin. Overall, higher protease concentration resulted in a larger loss of all vitamins. Among all tocopherols, $\alpha-T$ was the most affected, and $\delta$-T was the least affected. Neutrase and papain treatments increased $\delta$-T at lower enzyme concentrations (T1 to T3) but decreased $\delta$-T at higher enzyme concentrations (T4 and T5). The highest losses of $\alpha-, \gamma$-, and $\delta$-tocopherols were $60.87 \%, 40.60 \%$ and $36.89 \%$, respectively. Among B vitamins, B1 (Thiamine), was the most affected by Neutrase followed by Papain and Alcalase, whereas B2 was the most affected by papain but the least affected by Alcalase. Niacin (B3) was the most affected by Alcalase but least affected by Neutrase. B6 was the most affected by Alcalase but least affected by bromelain. The maximum losses of vitamins B1, B2, B3 and B6 were $63.29 \%, 44.83 \%, 40.56 \%$ and $49.59 \%$, respectively. As part of protease treatment approach, vacuum drying reduced $\alpha$-T by $23.9 \%$, but increased $\gamma$-T and $\delta$-T by $21.46 \%$ and $110.86 \%$. The reductions of vitamin B1, B2, B3 and B6 due to drying were $21.04 \%,-2.82 \%, 9.90 \%$ and $10.10 \%$, respectively. Thereby, the changes of tocopherols and B-vitamins include the changes caused by enzyme treatment and drying thereafter. 
Table 4. Percentage losses of tocopherols and B vitamins after treatment with four different proteases

\begin{tabular}{|c|c|c|c|c|c|c|c|c|c|}
\hline \multirow{2}{*}{ Protease } & \multirow{2}{*}{ Treatment } & \multirow{2}{*}{$\begin{array}{l}\text { Enzyme } \\
\text { Conc. }(\%)\end{array}$} & \multicolumn{7}{|c|}{ Loss of tocopherols and B vitamins (\%) } \\
\hline & & & $\alpha-T$ & $8-T$ & $\delta$-T & B1 & B2 & B3 & B6 \\
\hline & UNT-VD* & 0.00 & 23.92 & -21.46 & -110.86 & 21.04 & -2.82 & 11.84 & 10.10 \\
\hline \multirow[t]{5}{*}{ Alcalase } & $\mathrm{T} 1$ & 1.00 & 35.39 & 28.06 & 9.40 & 46.70 & -5.26 & 16.95 & 25.69 \\
\hline & $\mathrm{T} 2$ & 2.00 & 40.99 & 33.95 & 13.80 & 47.79 & -4.63 & 25.74 & 35.91 \\
\hline & T3 & 3.00 & 46.01 & 37.98 & 31.36 & 48.16 & 11.56 & 28.25 & 43.41 \\
\hline & $\mathrm{T} 4$ & 3.50 & 50.17 & 36.78 & 31.87 & 54.91 & 16.91 & 33.17 & 48.52 \\
\hline & T5 & 4.00 & 54.17 & 40.60 & 36.89 & 61.86 & 29.13 & 40.56 & 49.59 \\
\hline \multirow{5}{*}{ Bromelain } & $\mathrm{T} 1$ & 0.02 & 25.90 & -3.63 & 5.52 & 54.17 & 14.75 & 21.91 & 24.89 \\
\hline & $\mathrm{T} 2$ & 0.04 & 35.28 & 7.26 & 14.53 & 55.18 & 11.17 & 23.26 & 20.29 \\
\hline & T3 & 0.08 & 43.62 & 18.23 & 19.72 & 51.51 & 20.33 & 24.42 & 19.42 \\
\hline & $\mathrm{T} 4$ & 0.16 & 39.48 & 3.26 & 8.60 & 56.46 & 20.19 & 30.88 & 23.62 \\
\hline & T5 & 0.20 & 51.51 & 19.18 & 23.67 & 52.89 & 33.77 & 31.88 & 23.11 \\
\hline \multirow[t]{5}{*}{ Neutrase } & $\mathrm{T} 1$ & 0.20 & 37.43 & 9.81 & -26.03 & 55.86 & 10.49 & 14.27 & 29.66 \\
\hline & $\mathrm{T} 2$ & 0.40 & 37.36 & 15.56 & -14.09 & 52.33 & 33.38 & 15.07 & 28.72 \\
\hline & $\mathrm{T} 3$ & 0.80 & 41.07 & 21.41 & -8.54 & 50.43 & 27.26 & 17.68 & 27.92 \\
\hline & $\mathrm{T} 4$ & 1.20 & 50.10 & 25.90 & 9.63 & 58.59 & 44.83 & 25.88 & 32.88 \\
\hline & T5 & 1.60 & 50.15 & 28.25 & 11.13 & 63.29 & 42.63 & 28.84 & 38.06 \\
\hline \multirow[t]{5}{*}{ Papain } & $\mathrm{T} 1$ & 0.10 & 18.50 & -2.51 & -55.40 & 49.89 & 18.70 & 18.37 & 27.34 \\
\hline & $\mathrm{T} 2$ & 0.20 & 37.59 & 9.91 & -21.71 & 53.96 & 19.68 & 20.12 & 19.90 \\
\hline & $\mathrm{T} 3$ & 0.30 & 43.09 & 11.72 & -3.21 & 51.62 & 15.26 & 25.00 & 17.38 \\
\hline & $\mathrm{T} 4$ & 0.40 & 49.41 & 15.33 & 0.22 & 57.58 & 42.19 & 37.69 & 19.14 \\
\hline & $\mathrm{T} 5$ & 0.50 & 60.87 & 23.48 & 15.47 & 62.71 & 44.42 & 34.51 & 28.90 \\
\hline
\end{tabular}

*UNT-VD: Untreated, vacuum dried peanuts.

Bold data: The negative values indicate increased detectable vitamin due to drying or protease treatment at low enzyme concentrations compared with untreated raw peanut sample.

\section{Discussion}

\subsection{The Effects of Protease Treatments on the Contents of Vitamins in Raw Peanuts}

In this study, three main tocopherols identified in raw peanuts were $\alpha$-, $\gamma$-, and $\delta$ - tocopherols. Their contents in the raw untreated peanuts (UNT) detected by HPLC were 34.02, 12.32 and $1.0 \mathrm{mg} / 100 \mathrm{~g}$, respectively, in the order of $\alpha-\mathrm{T}>\gamma-\mathrm{T}>\delta$-T, suggesting that the $\alpha-\mathrm{T}$ is the dominant tocopherol in peanut. The contents of these tocopherols in untreated raw peanuts are in the range reported by Ahmed \& Young (1982). The concentrations of vitamins B1, B2, B3, and B6 in the untreated raw peanuts (UNT) were $0.27,0.44,11.88$, and $0.78 \mathrm{mg} / 100 \mathrm{~g}$, respectively, within the ranges reported by Ahmed \& Young (1982) but were lower than those reported in another study (King, Blumberg, Ingwersen, Jenab, \& Tucker, 2008). This might be due to difference in peanut cultivar, growing location, harvest time, processing etc. (Pattee, Isleib, Giesbrecht, \& McFeeters, 2000).

The influence of protease treatment on the content each vitamin varied with the type of enzyme, enzyme concentration, and individual vitamin stability (Figure 1-4). High protease concentrations resulted in larger loss of tocopherols and B vitamins although some vitamins were less affected by protease concentration (Table 4). The highest tocopherol loss occurred at Alcalase concentration 3.5-4\% where highest allergen reduction and lowest in vitro allergenicity were achieved (Yu \& Mikiashvili, 2020). The extent of tocopherol reduction in the peanuts due to proteolytic hydrolysis was in the order of $\alpha-T>\gamma-T>\delta$-T. The higher loss of $\alpha-T$ is because $\alpha$-tocopherol is the most reactive and less stable due to its lower bond dissociation energies (Silva et al., 2010; Keen \& Hassan, 2016; Shahidi \& Costa de Camargo, 2016; Decker \& Elias, 2016). Some studies about the effects of enzyme treatment on tocopherol content of oil seeds presented contradict results. For example, one study found that enzymatic aqueous (Alcalase $2.4 \mathrm{~L}$ ) extraction of sunflower seeds resulted in similar oil yield but lower total tocopherol content in the oil than common cold press (Ribeiro et al., 2016); while another study found that the enzyme-assisted oil extraction with a mixture of $\alpha$-amylase, Alcalase and Celluclast increased tocopherol content in the tiger nut oil (Ezeh et al., 2016). Due the differences in food matrix and enzyme treatment condition, it is difficult to compare the results of our study with the results of other studies. Because protease treatment of peanuts was conducted in the water-based enzyme solution and B vitamins are water-soluble, significant losses in B vitamins due to dissolution/leaching were expected. For example, the loss 
of B vitamins in vegetables by steaming is much lower than by cooking in water (Hwang et al., 2012; Veda et al., 2006).

The losses of vitamins during enzyme treatment is most likely caused by dissolution and protease treatment could enhance vitamin dissolution because the breakdown of protein molecules could create paths which allow vitamins leaching out from the inside of peanut kernels. In addition, the selectivity of protease used to treat peanuts might contribute to the differences in vitamin loss. Less selective protease has more cleave sites and will lead to more complete hydrolysis of proteins, thus more vitamin leaching. Among the four proteases used in this study, Alcalase is the least selective and can hydrolyze most of the peptide bonds (Yu \& Mikiashvili, 2020). This could explain the higher loss of B-vitamins in Alcalase treated peanuts (Table 4). Furthermore, the difference in treatment $\mathrm{pH}$ may be one of the contributing factors of B vitamin loss because the stability of B vitamins is affected by the $\mathrm{pH}$ of the food system. For instance, vitamin B1 is unstable in alkaline medium, B6 is more stable in acidic medium than in alkaline medium, while vitamin B2 and B3 are stable in both media (Gadient, 1986; Saidi \& Warthesen, 1983). The optimal pHs of Alcalase, bromelain, Neutrase, and papain are 7.5, 6.0, 7.0, and 7.0, respectively, and peanuts were treated at the optimal $\mathrm{pH}$ for each enzyme. This may partially explain the higher loss of vitamin B1 caused by Alcalase treatment and lower loss of B2, B3 and B6 caused by bromelain and papain treatment.

\subsection{Effect of Post-enzyme Treatment Drying on Vitamin Content in Peanuts}

In food industry, heating oil seeds prior to oil extraction is usually used to increase oil yield, but it can also induce changes to various components of the seed (Kraljić et al., 2018). Some studies found that heat treatment such as blanching and roasting caused loss of $\alpha$-tocopherol (Camargo et al., 2016; Shi et al., 2018), while other studies found 14 and $11 \%$ increase of $\gamma$-, and $\delta$ - tocopherol levels in peanuts after roasting at $140{ }^{\circ} \mathrm{C}$ for 20 min (Eitenmiller et al., 2011). Air-drying or microwave heating increased $\alpha$-, $\beta$ - and $\gamma$-tocopherol, but decreased $\delta$-tocopherol contents of grapeseed (Oomah et al., 1998). Roasting corn germ for 60 min at $125-175^{\circ} \mathrm{C}$ or microwave irradiation at $40-80 \mathrm{~W}$ for $4-8 \mathrm{~min}$ also significantly increased the oil yield and $\alpha-\beta-$ and $\gamma$-tocopherol contents but did not change $\delta$ - tocopherol content in the corn oil (Zheng et al., 2018). It was reported that roasting decreased the content of thiamine in tree nuts such as almond, walnut, and hazelnut, but minimally affected riboflavin content (Stuetz et al., 2017). A recent study also found that riboflavin was heat-stable while the other vitamins were heat-labile (Tylicki et al., 2018). This study shows significant loss of $\alpha$-tocopherol and B vitamins, as well as the increase of $\gamma$ - and $\delta$-tocopherols caused by vacuum drying. These examples suggest that the influence of heat treatment on tocopherols and B vitamins of oil seed varies with the food matrix, temperature and treatment time. Thus, the increase $\gamma$ - and $\delta$ - tocopherols in enzyme-treated peanuts might be caused by drying at low temperature $\left(75^{\circ} \mathrm{C}\right)$ which might increase the extractability of these tocopherols. Because drying was part of the treatment in this study, and the total loss of tocopherols and B-vitamins should be the sum of the loss during enzyme treatment and the loss/gain caused by vacuum drying.

\subsection{The Effect of Protease Treatment on Vitamin Intake from Peanuts}

The recommended daily allowance (RDA) of vitamin $\mathrm{E}$ for both male and female adults aged 14 years and above $15 \mathrm{mg}(\mathrm{NIH}, 2020)$. The levels of $\alpha$-tocopherol and total vitamin $\mathrm{E}$ in the peanuts treated with Alcalase, bromelain, Neutrase, and papain at their highest concentrations (T5) used in this study were 15.64, 16.54, 17.00, and $13.35 \mathrm{mg} / 100 \mathrm{~g}$ peanuts, and $23.54,27.22,26.69$, and $23.59 \mathrm{mg} / 100 \mathrm{~g}$ peanuts, respectively. Consuming one serving $(28 \mathrm{~g})$ of enzyme-treated peanut per day can provide more than $1 / 3$ of daily recommended vitamin $\mathrm{E}$ intake. Therefore, even though the treatments of peanuts reduced the contents of tocopherols, the treated peanuts still a good source of vitamin $\mathrm{E}$.

Similarly, the RDA of vitamin B1, B2, B3 and B6 for adults are 1.1-1.2, 1.0-1.3, 14-16, 1.2-1.3 mg (NIH, 2020). At the protease concentrations where highest allergen reduction was achieved, the remaining vitamin B1, B2, B3 and B6 contents in peanuts were $0.12,0.37,10.02$ and $0.40 \mathrm{mg} / 100 \mathrm{~g}$, respectively. This shows that consumption of 3 servings (approximately $100 \mathrm{~g}$ ) of peanuts treated with enzymes may provide 10-12\% of RDA of thiamine, 21-33\% RDA of riboflavin, 71-76 \% RDA of niacin and 31-48 \% of pyridoxine. These values, except thiamine, are consistent with the RDA equivalent per $100 \mathrm{~g}$ of untreated peanuts reported in the USDA nutrient composition database (Arya et al., 2016). Human beings usually obtain their B vitamins from grain, meat and eggs, while vegans may need consume more nuts or take B vitamin supplement to meet the dietary requirement of B vitamin intake.

\section{Conclusion}

In conclusion, this study demonstrates that peanut allergen reduction approach using non-specific proteases (including enzyme treatment and drying) resulted in significant losses of tocopherols and B vitamins although 
the treatment greatly reduced the allergen content and immunoreactivity of peanuts as shown in our previous studies (Yu \& Mikiashvili, 2020). The degree of vitamin loss was influenced by the type of enzyme, enzyme concentration, and individual vitamin stability. Overall, papain and Alcalase treatments had larger impacts on tocopherols than bromelain and Neutrase. The $\alpha$-tocopherol was the most affected among all tocopherols due to its instability, while $\delta$-tocopherol was the least affected. Among all B vitamins investigated, vitamin B1 was the most affected and B3 was the least affected. Higher enzyme concentration resulted in a more significant loss of each vitamin. However, the enzyme treated peanuts is still a good source of tocopherols and vitamin B3 comparing to most cooked legumes (Margier et al., 2018) and vegetables (Knecht et al., 2015). Consuming one serving ( $28 \mathrm{~g}$ ) of enzyme-treated peanut per day can provide more than $1 / 3$ of daily recommended vitamin $\mathrm{E}$ intake and 20-25\% of vitamin B3 intake. Vitamin enrichment may not be required if treated peanuts are consumed with other food products rich in B vitamins, but the enrichment may be necessary if the enzyme treated peanuts are used to combat malnutrition.

\section{Acknowledgement}

This research is funded by National Institute of Food and Agriculture, the United State Department of Agriculture. Grant number NC.X-307-5-17-170-1.

\section{Conflicts of Interest}

The authors declare no conflict of interest.

\section{References}

Abumweis, S., Barake, R., \& Jones, P. (2008). Plant sterols/stanols as cholesterol lowering agents: A meta-analysis of randomized controlled trials. Food \& Nutrition Research, 52, 1811. https://doi.org/10.3402/fnr.v52i0.1811

Ahmed, E. M., \& Young, C. T. (1982). Composition, quality and flavor of peanuts. In H. E. Pattee \& C. T. Young (Eds.), Peanut Science and Technology (pp. 655-688). Yoakum, Texas: American Peanut Research and Education Society, Inc.

Ahsan, H., Ahad, A., \& Siddiqui, W. A. (2015). A review of characterization of tocotrienols from plant oils and foods. Journal of Chemical Biology, 8(2), 45-59. https://doi.org/10.1007/s12154-014-0127-8

Arya, S. S., Salve, A. R., \& Chauhan, S. (2016). Peanuts as functional food: a review. Journal of Food Science and Technology, 53(1), 31-41. https://doi.org/10.1007/s13197-015-2007-9

Awad, A. B., Chan, K. C., Downie, A. C., \& Fink, C. S. (2000). Peanuts as a source of $\beta$-sitosterol, a sterol with anticancer properties. Nutrition and Cancer, 36(2), 238-241. https://doi.org/10.1207/S15327914NC3602_14

Bock, S. A., Muñoz-Furlong, A., \& Sampson, H. A. (2007). Further fatalities caused by anaphylactic reactions to food. Journal of Allergy and Clinical Immunology, 119(1), 1016-1018. https://doi.org/10.1016/j.jaci.2006.12.622

Cai, C. X., Carlos, S., Solaimani, P., Trivedi, B. J., Tran, C., \& Castelino-Prabhu, S. (2019). Nutritional and dietary interventions for nonalcoholic fatty liver disease. In R. R. Watson \& V. R. Preedy (Eds.), Dietary Interventions in Liver Disease (pp. 357-372). Academic Press, San Diego, CA. https://doi.org/10.1016/b978-0-12-814466-4.00029-x

Camargo, A. C. D., Regitano-Darce, M. A. B., Alencar, S. M. D., Canniatti-Brazaca, S. G., Thais Maria Ferreira De Souza Vieira, \& Shahidi, F. (2016). Chemical changes and oxidative stability of peanuts as affected by the dry-blanching. Journal of the American Oil Chemists Society, 93(8), 1101-1109. https://doi.org/10.1007/s11746-016-2838-1

Chen, L., Liu, Z., Kang, X., Zhou, X., Zheng, S., \& Gu, Z. (2011). Determination of fat-soluble vitamins in food and pharmaceutical supplements using packed-fiber solid phase extraction (PFSPE) for sample pre-concentration/ clean-up. Procedia Environmental Sciences, 8(1), 588-595. https://doi.org/10.1016/j.proenv.2011.10.091

Decker, E. A., \& Elias, R. J. (2016). Oxidation in foods and beverages and antioxidant applications: understanding mechanisms of oxidation and antioxidant activity (1st Ed.). Woodhead Pub Ltd, Philadelphia, PA, USA.

Eitenmiller, R. R., Choi, S.-G. R., \& Chun, J. R. (2011). Effects of Dry Roasting on the Vitamin E Content and Microstructure of Peanut (Arachis hypogaea). Journal of Agriculture \& Life Science, 45(2), 121-133.

Ezeh, O., Niranjan, K., \& Gordon, M. H. (2016). Effect of enzyme pre-treatments on bioactive compounds in 
extracted tiger nut oil and sugars in residual meals. Journal of American Oil Chemists' Society, 93, 1541-1549. https://doi.org/10.1007/s11746-016-2883-9

Gadient, M. (1986). Effect of pelleting on nutritional quality of feed. In Proceeding: 1986 Maryland Nutrition Conference Feed Manufacturers, College Park, Maryland, USA.

Gupta, R. S., Warren, C. M., Smith, B. M., Jiang, J., Blumenstock, J. A., Davis, M. M., Schleimer, R. P., \& Nadeau, K. C. (2019). Prevalence and severity of food allergies among US adults. JAMA Network Open, 2(1), 185630. https://doi.org/10.1001/jamanetworkopen.2018.5630

Hwang, I. G., Shin, Y. J., Lee, S., Lee, J., \& Yoo, S. M. (2012). Effects of Different Cooking Methods on the Antioxidant Properties of Red Pepper (Capsicum annuum L.). Preventive Nutrition and Food Science, 17(4), 286-292. https://doi.org/10.3746/pnf.2012.17.4.286

Jiang, J., Bushara, O., Ponczek, J., Warren, C., Blumenstock, J., Smith, B., \& Gupta, R. (2018). Updated pediatric peanut allergy prevalence in the United States. Annals of Allergy, Asthma \& Immunology, 121(5), 14. https://doi.org/10.1016/j.anai.2018.09.042

Keen, M. A., \& Hassan, I. (2016). Vitamin E in dermatology. Indian Dermatol Online Journal, 7(4), $311-315$. https://doi.org/10.4103/2229-5178.185494

King, J. C., Blumberg, J., Ingwersen, L., Jenab, M., \& Tucker, K. L. (2008). Tree Nuts and Peanuts as Components of a Healthy Diet. The Journal of Nutrition, 138(9). https://doi.org/10.1093/jn/138.9.1736s

Knecht, K., Sandfuchs, K., Kulling, S. E., \& Bunzel, D. (2015). Tocopherol and tocotrienol analysis in raw and cooked vegetables: A validated method with emphasis on sample preparation. Food Chemistry, 169, $20-27$. https://doi.org/10.1016/j.foodchem.2014.07.099

Kraljić, K, Stjepanović, T., Obranović, M., Pospišil, M., Balbino, S., \& Škevin, D. (2018). Influence of conditioning temperature on the quality, nutritional properties and volatile profile of virgin rapeseed oil. Food Technol. Biotechnol, 56(4), 562-572. https://doi.org/10.17113/ftb.56.04.18.5738

Medina-Juárez, L. A., Campos-Mondragón, M. G., Calderón De La Barca A. M., Durán-Prado, A., Campos-Reyes, L. C., Oliart-Ros, R. M., \& Angulo, O. (2009). Nutritional composition of new peanut (Arachis hypogaea L.) cultivars. Grasas y Aceites, 60(2), 161-167. https://doi.org/10.3989/gya.075008

Margier, M., Georgé, S., Hafnaoui, N., Remond, D., Nowicki, M., Du Chaffaut, L., Marie-Josèphe Amiot, M. J., \& Reboul, E. (2018). Nutritional composition and bioactive content of legumes: characterization of pulses frequently consumed in France and effect of the cooking method. Nutrients, 10, 1668. https://doi.org/10.3390/nu10111668

NIH. (2020). Dietary Reference Intakes (DRIs): Recommended Dietary Allowances and Adequate Intakes, Vitamins. Retrieved from https://www.ncbi.nlm.nih.gov/books/NBK56068/table/summarytables.t2/?report=objectonly

Nwaru, B. I., Hickstein, L., Panesar, S. S., Roberts, G., Muraro, A., \& Sheikh, A. (2014). Prevalence of common food allergies in Europe: a systematic review and meta-analysis. Allergy, 69(8), 992-1007. https://doi.org/10.1111/all.12423

Oomah, B. D, Liang, J., Godfrey, D., \& Mazza, G. (1998). Microwave heating of grapeseed: effect on oil quality. Journal of Agricultural and Food Chemistry, 46, 4017-4021. https://doi.org/10.1021/jf980412f

Pattee, H. E., Young, C. T., Pearson, J. L., Singleton, J. A., \& Giesbrecht, F. G. (1982). Storage and Moisture Effects on Peanut Composition and Roasted Flavor1. Peanut Science, 9(2), 98-101. https://doi.org/10.3146/i0095-3679-9-2-14

Pattee, H. E., Isleib, T. G., Giesbrecht, F. G., \& McFeeters, R. F. (2000). Investigations into genotypic variations of peanut carbohydrates. Journal of Agricultural and Food Chemistry, 48, 750-756. https://doi.org/10.1021/jf9910739

Ribeiro, S. A. O., Nicacio, A. E. N., Zanqui, A. B., Biondo, de Abreu-Filho, B. A., Visentainer, J. V., Gomes, S. T. M., \& Matsushita, M. (2016). Application of enzymes in sunflower oil extraction: antioxidant capacity and lipophilic bioactive composition. Journal of Brazil Chemical Society, 27(5), 834-840. https://doi.org/10.5935/0103-5053.20150335

Saidi, B., \& Warthesen, J. J. (1983). Influence of pH and light on the kinetics of vitamin B6 degradation. Journal of Agricultural and Food Chemistry, 31, 876-880. https://doi.org/10.1021/jf00118a051 
Settaluri, V. S., Kandala, C. V. K., Puppala, N., \& Sundaram, J. (2012). Peanuts and their nutritional aspects-A Review. Food and Nutrition Sciences, 3(12), 1644-1650. https://doi.org/10.4236/fns.2012.312215

Shahidi, F., \& Costa De Camargo, A. (2016). Tocopherols and tocotrienols in common and emerging dietary sources: occurrence, applications, International journal of Molecular Science, 17(10), 1745. https://doi.org/10.3390/ijms17101745

Shi, X., Dean, L. O., Davis, J. P., Sandeep, K., \& Sanders, T. H. (2018). The effects of different dry roast parameters on peanut quality using an industrial belt-type roaster simulator. Food Chemistry, 240, 974-979. https://doi.org/10.1016/j.foodchem.2017.07.130

Silva, M. P., Martinez, M. J., Casini, C., Grosso, N. R. (2010). Tocopherol content, peroxide value and sensory attributes in roasted peanuts during storage. International Journal of Food Science \& Technology, 45(7), 1499-1504. https://doi.org/10.1111/j.1365-2621.2010.02293.x

Stuetz, W., Schlörmann, W., \& Glei, M. (2017). B-vitamins, carotenoids and $\alpha$ - $\gamma$-tocopherol in raw and roasted nuts. Food Chemistry, 221(1), 222-227. https://doi.org/10.1016/j.foodchem.2016.10.065

Trang, H. K. (2013). Development of HPLC methods for the determination of water-soluble vitamins in pharmaceuticals and fortified food products. All Theses. 1745. Clemson University. Retrieved from https://tigerprints.clemson.edu/all_theses/1745

Tylicki, A., Łotowski, Z., Siemieniuk, M., \& Ratkiewicz, A. (2018). Thiamine and selected thiamine antivitamins - biological activity and methods of synthesis. Bioscience Reports, 38(1). https://doi.org/10.1042/BSR20171148

USDA. (2015). USDA National Nutrient Database for Standard Reference, Release 28 (2015). Retrieved from https://www.ars.usda.gov/ARSUserFiles/80400535/Data/SR/SR28/reports/sr28fg16.pdf

USDA. (2018). USDA Food Composition Database. Retrieved from https://ndb.nal.usda.gov/ndb/

Veda, S., Kamath, A., Platel, K., Begum, K., \& Srinivasan, K. (2006). Determination of bioaccessibility of $\beta$-carotene in vegetables by in vitro methods. Molecular Nutrition \& Food Research, 50(11), 1047-1052. https://doi.org/10.1002/mnfr.200600076

Whitney, E. N., \& Rolfes, S. R. (2019). Understanding nutrition. (15th ed.). Boston: Cengage Learning Custom Publishing.

Woollard, D. C., \& Indyk, H. E. (2002). Rapid determination of thiamine, riboflavin, pyridoxine, and niacinamide in infant formulas by liquid chromatography. Journal of AOAC International, 85(4), 945-51. https://doi.org/10.1093/jaoac/85.4.945

Yadav, P. B., Edukondalu, L., Patel, S., \& Rao, D. B. (2018). Proximate composition of peanut milk prepared by different methods. International Journal of Current Microbiology and Applied Sciences, 7(10), 2388-2391. https://doi.org/10.20546/ijcmas.2018.710.276

Yu, J., \& Mikiashvili, N. (2020). Effectiveness of different proteases in reducing allergen content and IgE-binding of raw peanuts. Food Chemistry, 307, 125565. https://doi.org/10.1016/j.foodchem.2019.125565

Yu, J., Hernandez, M., Li, H., Goktepe, I., Robinette, C., Auerbach, A., Peden, D., \& Ahmedna, M. (2015). Allergenicity of roasted peanuts treated with a non-human digestive protease. Food Research International, 69(1), 341-347. https://doi.org/10.1016/j.foodres.2015.01.007

Zheng, L., Jin, J., Huang, J., Yue Wang, Y., Korma, S.A., Wang, X., \& Jin, Q. (2018). Effects of heat pretreatment of wet-milled corn germ on the physicochemical properties of oil. Journal of Food Science and Technology, 55, 3154-3162. https://doi.org/10.1007/s13197-018-3243-6

\section{Copyrights}

Copyright for this article is retained by the author(s), with first publication rights granted to the journal.

This is an open-access article distributed under the terms and conditions of the Creative Commons Attribution license (http://creativecommons.org/licenses/by/4.0/). 